Natalia Grincheva:

\title{
Psychotechnologies of Digital Diplomacy
}

\begin{abstract}
:
The study outlines the problematic framework of the emerging field of digital diplomacy in the social, cultural, and economic dimensions through a close reading of Stiegler's philosophical concept of the techno-culture. The research intends to raise important questions regarding international communications in a new light of phenomenology of collective individuation. Stiegler's philosophical conception of contemporary politics under the condition of globalized cultural and economic capitalism is one way to explain the dramatic changes in diplomatic relations taking place on the global arena at the beginning of the new century. Stiegler's techno-cultural project has significant implications for digital diplomacy as a practical discipline and can be successfully utilized to improve its future development based on the more productive engagement with social, economic, and political issues in a theoretical context. The study tries to deepen the understanding of the political and economic mechanisms in the international communication and diplomatic activities complicated and challenged with the advance of digital technologies in the global capitalism system.
\end{abstract}

\section{Agenda:}

Introduction

\section{Author:}

Natalia Grincheva:

- Centre for Interdisciplinary Studies in Society and Culture (CISSC), Concordia University, Montreal, Canada

- 甶 + $13233364496, \bowtie$ grincheva@hotmail.com

- Relevant publications:

- Grincheva, N.: How Far Can We Reach? The International Journal of Technology, Knowledge and Society, 7-4, 2012

- Grincheva, N.: U.S. Arts and Cultural Diplomacy: Post-Cold War Decline and the Twenty-First Century Debate. The Journal of Arts Management, Law, and Society, 40-3, 2010 


\section{Introduction}

In the complex processes of economic and cultural globalization, many countries (especially in Western economically developed societies) try to preserve their cultural diversity and strive to make their national heritage and contemporary cultures more accessible to people around the world. Digital diplomacy has become a new and increasingly popular political strategy that aims to provide open access to cultural content and create a new way of interaction with global audiences. In recent years, many national cultural industries have been engaged in developing digital platforms for the preservation and promotion of cultural heritage. These national cultural assets decoded in digital networks serve to develop political sites specifically designed to communicate cultural citizenship through various forms of cultural inclusion and participation (Paschalidis 2010, 179).

Diplomacy has traditionally served to manage relations among states and other parties by advising and shaping foreign policy, which eventually coordinates and secures specific states' interests in the international arena. With the advance of new media communication tools, diplomacy, and specifically cultural diplomacy, is increasingly adopting new dimensions and developing a genuine "communicative action" (Plavsak 2002, 110). Digital diplomacy, also known as diplomacy 2.0 or e-diplomacy, incorporates the inclusive nature of traditional public or cultural diplomacy and in many ways is a derivative of the above-mentioned definition. Therefore, digital diplomacy mainly refers to the diplomatic practices through digital and networked technologies, including the Internet, mobile devices, and social media channels (Potter 2002).

Though in last decade digital diplomacy has been the focus of close attention from political leaders and cultural practitioners, there is still a lack of academic engagement with this subject in a more critical and theoretical context. However, it is imperative to better understand how these technologies of externalizing cultural memory, national heritage, and identity, as well as human values, work within a larger political context in global communications. This paper aims to elaborate the theoretical underpinnings of digital diplomacy through employing the conceptual framework of collective individuation and psychotechnologies developed by French critical philosopher Bernard Stiegler.

In his series Technics and Time, Stiegler demonstrated that human agency is always in need of technical extension and support to sustain oneself and realize individual and collective goals. As such, "technical prosthesis" has always been critical for humans, making possible its ever becoming (Stiegler 1998, 188). Most importantly, the cultural phenomenon of human memory influencing the construction of future development becomes possible only with the advent of techniques and tools. These tools serve as external virtual drives of human experiences and knowledge memory that shape the future, inherited from those past lives of which it is the crystallized exteriorization. Exteriorization as the formation of the techno-cultural context of human sociality is always in reciprocal, co-constitutive relationship to interiorization, which is the process of individual consciousness formation (Stiegler 1998, 163).

Stiegler's conception of memory exteriorization is crucial for the present study because it helps to analyze audio-visual and digital technologies in its major influence on human consciousness being formed from the outside. These technologies, according to Stiegler, have a strong potential to impact human cognitive processes constituting consciousness outside of real life experiences. Technical audio-visual and digital objects and tools build future experiences in contemporary society, out of which the principles for memory selectively emerge to preserve the primary moments in an ongoing real-time montage of the present. In line with Walter Benjamin's concern about the political implications of the technological advance in cultural sphere, Steigler in his work demonstrates how tele and digital technologies revolutionised communication techniques, employed by governments and commercial industries to manipulate and control audiences on national and transnational levels. Digital, electronic dimensions of modern exteriorization technology, as Stiegler emphasizes, is resultant in erosion of national collective memory being programmed under the contradictory economic and cultural globalization forces in a political struggle for manipulating human consciousness. 


\section{Phenomenology of Collective Memory: Transindividuation Processes in the Information Society}

To better explain the political processes of psychotechnologies in relation to digital diplomacy, it is important to define such notions as individuation and collective individuation or transindividuaton (used in this paper interchangeably). These notions first introduced by Gilbert Simondon (1989) are critical initial points for understanding larger concepts of political and economic powers that are analyzed in this paper in light of digital diplomacy. The notion of individuation is constructed on the premise that an "individual" is never given in advance but produced or come into being in the course of multiple ongoing processes. Individuation occurs as a complex interaction of multidimensional processes, some of which can also take place transindividually, or on a group level (Simondon 1989, 128). Transindividuation is a foundation of another layer of environment created through collective meanings. In transindividuation, senses are perceived and transmitted through members of communities, modified and shaped by each one through human communication, thus making collective and subjective life possible.

Before explaining transindividuation, there is the need to refer to another concept from Simondon, transduction. Transduction accounts for a mediating process between the world and a living being, which develops a psychic individuation. Such an "exchange of energies" with a world to which any individuation is fully integrated produces a subject, a psychic being separated from the world, but interacting with it as a whole other phase of being by itself (Simondon 1989, 24-25).

One of the most important points of transduction theory that is being challenged and further questioned in the realm of digital technologies is Simondon's claim that "transduction is any transfer of information through a material medium. It applies to processes of differentiation and crystallization of all sorts, from the growth of an embryo, to the learning of a concept, to the spread of what today are called "memes" through a society" (Shaviro 2006). However, with the development of new media information technologies and a global reach of the Internet, humanity has been increasingly infected with the ideas of information's immateriality (Hayles 2004). Digital technologies have created an unlimited storage capacity to preserve, share, and exchange digitally decoded human heritage and any sort of information accumulated by the present and past generations. Thus, information often seems independent of materiality, but transduction, as Simondon points out, is never independent of its material medium. Therefore, in accordance with McLuhan's famous thesis "media is the message" (1967), Simondon also asserts that the medium and message intersect. The shape of the information transmitted within a medium is in important ways transformed through the qualities and potential of the medium.

The digital medium, specifically the Internet, is a type of medium that in many ways redefines the principles of mass communications and provides a techno-geographical milieu of connected minds where the circulation of information shapes the consciousness of people through a transduction bypassing physical boundaries. Stalder also confirms that with the advance of the Internet, network technology culture has been transformed from an object-oriented to exchange-oriented culture, which is understood as a continuous process (Stalder 2005). The exchange-oriented culture corresponds nicely to Manuel Castells' perspective on the growth of a networked society, where culture consists not so much of content, but of processes; and where the Internet is "an openended network of cultural meanings that can not only coexist, but also interact and modify each other on the basis of this exchange" (Castells, 2004, 40).

Stiegler, discussing the processes of globalization and virtualization of contemporary culture, indicates that "...an increase in digital networking will produce a new kind of temporal object: one that is delinearizable and inseparable, produced by hypervideo technologies" (Stiegler 2011, 3). He sees the future of humanity in light of the increased technotization of human consciousness:

there will doubtless be an increase in the amount of time spent in front of screens of all kinds, which will be then re-conceptualized and redefined in their functions (becoming terminals of tele-action), their various applications expanding into the thousands, most notably at the professional level; these processes will pursue, at an increasingly complex level and with increasing ease and sensitivity, the industrial temporalization of consciousness (Stiegler 2011, 3). 
By temporal objects, Stiegler means films, radio, television programs, and other media products which reach out daily "to millions, hundreds of millions of consciousnesses" (Stiegler 2009, 106). These temporal objects, as Stiegler explains, represent the pursuit of life by means other than life (Stiegler 1998, 17). Stiegler introduces the notion of the temporal object in regard to his theoretical concept of the collective memory. Stiegler's exploration of the technologies of human consciousness manipulation, or tele-technologies as he called them, started from his detailed analysis of audiovisual media, such as cinema, and progressed to the study of digital technologies in his most recent works. However, his framework of tele-technologies, in the broadest sense, serves as a playground for exploration of the "industrialization of memory."

The industrialization of human memory, which includes culture and identity, is now operationalized through the production and wide distribution of industrial temporal objects. The results of industrialization or exteriorization of human memory in temporal objects create technical collective memory, which plays a crucial role in shaping all aspects of life in society, because it contains collective experiences from which anybody can draw and thus, project into the future and transform existence.

According to Stiegler, collective memory is a specific form of actualization of the present rather than the conjunction of a human being with an image of the past. The present moment is being actualized via the flow of time and space captured through temporal objects that are the result of a highly selective process of cultural contextualization and are extremely political by nature (Stiegler, 1998, 68). As Stiegler explains, the qualities of temporal objects are able to attract predetermined ways of viewing the past and reconstructing the present. They are the carrier of collective knowledge, experiences, and ideas that people have had. However, their structure of inheritance and transmission is not biological and genetic but external, which exists in addition to the genetic, like a surrounding layer. Stiegler emphasizes the individual ontogeneses, which exists beyond the central nervous system and is formed through culture, as collective knowledge, in interaction with technical artifacts (Stiegler, 1998, 72).

The mechanisms that are in place in the reconstruction of human experiences through interaction with temporal objects can be explained by the ability of these objects to represent the past of others while being in the present of an individual in a particular time and space. In this way, temporal objects give access to a past that one has not lived, the past as the "already there" or in Heideger's terms, the Dasein, only accessible through techniques. As a result, history, traditions, communities are instrumentalized and can be transmitted to human minds to build a collective memory (Stiegler, 1998, 85). In regard to cross-cultural interaction in a broad realm of political international communication, human culture serves as the medium of invention and propagation of collective memory.

Traditionally, collective memory has been understood as "becoming-together" in space with the material cultural objects: in museums, in public heritage sites, in films, in the nonstop stream of images, and in sounds surrounding people in their daily activities. As a result, television, cinema, and digital media enable billions of people around the globe share many key milestones, even though the perspectives of different cultural societies toward these images and ideas significantly differ. In a large measure, a collective memory is being produced on a global scale, and that collective memory serves as a common guideline to all those who live in the interior of a given social and historical configuration.

From an international relations and diplomatic perspective, Stiegler's emphasis on the power of particular cultural objects to dominate in the global context is imperative. Stiegler illustrates his idea of cultural domination through the case of the successful film industry in Hollywood being increasingly representative across countries and thus spreading the American lifestyle around the world. Stiegler argues that the U.S. film industry was able to dominate globally not because of the U.S. industrial power but because the United States needed to fully employ cinematic potential to produce effective stories to invent the country itself. In the case with the United States, the process of unification of a nation depended not so much on sharing a common historical past, but rather on projecting the desire for a common future. The rise of cinematography and culture was particularly acute in the case of the United States, because the country needed to stimulate individuals composing their common being. This required the constant projection of a model, which is known now as the "American way of life," and that amounts today to the consumerist model transmitted globally (Stiegler 2011, 105). 


\section{Conclusion}

From a political perspective, this power of temporal objects to reach and manipulate audiences across borders and dominate the cultural niches of other societies has strong implications in diplomatic relations. This framework is imperative because cultural diplomacy has traditionally been "an instrument ... and a way of interacting with the outside world" (Gienow-Hecht, Donfried 2010, 11). Cultural diplomacy implies the use of the art of diplomacy in promoting culture, resulting in greater awareness of each other's cultural backgrounds. Such awareness leads to interaction among various players, states, and individuals. Traditionally (and before the rapid advance of tele-technologies) it was achieved through organization of events or a series of cultural activities among countries, employing the instrumentality of "culture" in promoting a country's interests in economic, political, and strategic fields. Though defined as "the exchange of ideas, information, art and other aspects of culture among nations and their peoples to foster mutual understanding" (Cummings 2003), cultural diplomacy has served in many historical examples as a powerful tool of cultural propaganda and manipulation.

In regard to digital diplomacy, Stiegler's framework is particularly relevant to excitement in the diplomatic and international communication fields about the advance of the new media channels of trans-cultural interactions. The digital technologies provided means even faster and more efficient distribution of cultural content that can reach and manipulate millions of consciousnesses around the globe in milliseconds; "While broadcast networks are still necessarily national for technical and performance-transmission reasons, the digital network is global" (Stiegler 2011, 126).

As Hart confirms, "the increased speed of digital devices and innovations in computer networks and digital compression technologies make it both easier and less expensive to deliver words, music, symbols, and images (in fact, anything that can be digitized) to consumers around the world" (Hart 2010, 56). The hegemony of Hollywood increased even further with the development of new media and the domination of the Internet, which enabled simultaneous watching of live events by hundreds of millions of people.

Stiegler's techno-cultural project has significant implications for digital diplomacy as a practical discipline and can be successfully utilized to improve its future development based on the more productive engagement with social, economic, and political issues in a theoretical context. The technological advance of the information society, envisioned by many enthusiastic supporters of digital revolution as a huge progress in the postmodern struggle for democracy, brings about new challenges and threats to cultural development and cultural exchanges in the local, national, and international contexts. Close attention to the political questions raised by Stiegler in his series Technics and Time can help academics and practitioners from the digital diplomacy field to focus and address the most important moments of social cultural formations of contemporary networked society in a globalized community.

\section{References}

Benjamin, W.: The Work of Art in the Age of Mechanical Reproduction, Modern Art and Modernism: A Critical Anthology, SAGE 1982

Castells, M.: The Network Society: A Cross-Cultural Perspective. New York, Edward Edgar 2004

Cummings, M.: Cultural Diplomacy and the United States Government: A Survey. Center for Arts and Culture, vol. 1. 2003

Gienow-Hecht, J. and Donfried, M.: Searching for a Cultural Diplomacy. Berlin, Berghahn Books 2010

Hart, Jeffrey A.: Toward a Political Economy of Digital Culture: From Organized Mass Consumption to Attention Rivalry. In Singh J. International Cultural Policies and Power. Palgrave Macmillan 2010

Hayles, K.: Nanoculture: Implications of the New Technoscience. Intellect Books 2004

Paschalidis, G.: Digital Heritage in New Knowledge Enviroment. Athens Ministry of Culture 2010

Plavsak, K.: Communicative Diplomacy for the 3rd Millennium. Journal of Political Marketing. 1, 22002

Potter, E.H.: Cyber-Diplomacy: Managing Foreign Policy in the Twenty-First Century. McGill-Queen's Press MQUP 2002 
Shaviro, S.: Simondon in Individuation. The Pinocchio Theory 2006

Simondon, G.: Individuation Psychique et Collective. Aubier, Paris 1989

Stiegler, B.: Time and Technics 1: The Fault of Epimethus. Stanford, Stanford University Press 1998

Stiegler, B.:Technics of Decision an Interview. Angelaki, Journal of the Theoretical Humanities, 8-2, 2003

Stiegler, B.: Biopower, Psychopower and the Logic of the Scapegoat. The Philosophy of Technology: A Colloquium with Bernard 2008

Stiegler, B.: Teleologics of the Snail: The Errant Self Wired to a WiMax Network. Theory Culture Society, 2009

Stiegler, B.: Time and Technics 2: The Fault of Epimethus. Stanford, Stanford University Press 2009

Stiegler, B.: Taking Care of Youth and the Generations. Stanford, Stanford University Press 2010

Stiegler, B.: Telecracy against Democracy. Cultural Politics, 6-2, 2010

Stiegler, B.: Time and Technics 3: The Fault of Epimethus. Stanford, Stanford University Press 2011 